\title{
Association analysis between carcass weight and meat quality of Bamei pigs
}

\author{
J.P. Zhou ${ }^{1}$, G.F. Wu ${ }^{1 *}$, A.Q. Xiang ${ }^{2}$, L. Wang ${ }^{1}$, S.D. Sun ${ }^{2}$, C. Yang ${ }^{1}$ and \\ F.F. $\mathrm{Xu}^{3}$
}

${ }^{1}$ Stake Key Laboratory of Plateau Ecology and Agriculture, Qinghai Academy of Animal Science and Veterinary Medicine, Qinghai University, Xining, Qinghai, China

${ }^{2}$ College of Animal Science and Technology, Northwest A\& F University, Yangling, Shaanxi, China

${ }^{3}$ Qinghai Province Huzhu County Bamei Pig Seed Breeding Farm, Huzhu, Qinghai, China

Corresponding author: G.F. Wu

E-mail: letitbe521@163.com

Genet. Mol. Res. 15 (3): gmr.15037493

Received August 20, 2015

Accepted December 7, 2015

Published August 12, 2016

DOI http://dx.doi.org/10.4238/gmr.15037493

Copyright (C) 2016 The Authors. This is an open-access article distributed under the terms of the Creative Commons Attribution ShareAlike (CC BY-SA) 4.0 License.

\begin{abstract}
A total of 48 crossbred Bamei pig carcasses were divided into three groups (A, 60-69 kg; B, 70-79 kg; and C, 80-90 $\mathrm{kg}$ ) to investigate the influence of carcass weight on meat quality. The intramuscular fat content of the three groups increased from $2.20 \%$ (Group A) to $4.14 \%$ (Group C). Group B had higher drip loss $(6.83 \%, \mathrm{P}<0.05)$ than the other two groups. Warner-Bratzler shear force decreased with increasing weight $(61.16>51.63>43.64 \mathrm{~N}, \mathrm{P}<$ $0.05)$. No significant differences were observed in meat color, cooking percentage, and water holding capacity among the three groups. The polyunsaturated fatty acids/saturated fatty acids ratio in group $\mathrm{B}(0.23)$ was significantly higher than that in the other two groups. In conclusion,
\end{abstract}


our results suggested that a carcass weight of $70-79 \mathrm{~kg}$ is suitable for the production of Bamei pigs.

Key words: Carcass weight; Fatty acid composition; Bamei pig; Meat quality; Free amino acid composition

\section{INTRODUCTION}

Bamei pigs are a local variety of QingHai Province, which is a plateau that has permitted a long period of natural and artificial selection, leading to this pig variety having strong adaptability, fat deposition ability, and good meat quality characteristics (Jin, 2006; Yang and Gun, 2007). Results of hybridization experiments have shown that Bamei pigs are an excellent maternal, binary and trispecific hybrid pig showing better combining ability and heterosis. Binary and trispecific hybrid pigs are leaner, have larger hindquarters, and demonstrate better breeding performance than purebred Bamei pigs (Yang et al., 2010; Yang et al., 2011; Guo et al., 2012). However, few scientific studies have examined the meat quality of Bamei pigs, particularly with respect to the relationships between carcass, intramuscular fat (IMF) content, and fatty acid composition. Previous research has found that the adipose growth rate of Bamei pigs significantly increased after they reached $35 \mathrm{~kg}$, the muscle growth rate significantly decreased after the animals reached $55 \mathrm{~kg}$ (Yang and Song, 1991), and prolonged feeding wasted feed. It is important to determine a suitable carcass weight in order to obtain the best pork from Bamei pigs.

Muscle microstructure is an important determinate of meat quality, which affects muscle physicochemical traits. Postmortem changes affect fiber type composition in the conversion of muscle to meat, and thus affect meat quality (Ryu and Kim, 2006). In pigs, a larger muscle fiber cross-sectional area is thought to be detrimental to meat quality, owing to its poor water-holding capacity and tenderness (Rehfeldt et al., 2000). However, IMF content and fatty acid composition also affect the nutritional quality of muscle, and have been widely studied in meat science because of their importance to human health (Pfeuffer, 2001; Raes et al., 2004). Therefore, we investigated suitable carcass weights and assessed the relationship between this trait and meat quality from Bamei pigs.

\section{MATERIAL AND METHODS}

All experimental procedures were performed according to the Guide for Animal Care and Use of Laboratory Animals in the Institutional Animal Care and Use Committee of QingHai University. The experimental protocol was approved by the Department of Animal Ethics Committee of QingHai University.

\section{Animals and management}

A total of 48 Bamei Pigs, ranging from 60 to $90 \mathrm{~kg}$ in carcass weight, were selected and divided into three weight groups containing 16 carcasses each: A, 60-69 $\mathrm{kg}$ (8 months old); B, $70-79 \mathrm{~kg}$ (10 months old); and C, 80-90 kg (12 months old). All pigs were fed ad libitum with a commercial diet (Table S1) suited to their nutritive needs. The pigs were fasted and given free access to water for $16 \mathrm{~h}$, and were then electrically stunned, exsanguinated, scalded, and rinsed.

Genetics and Molecular Research 15 (3): gmr.15037493 


\section{Carcass and meat quality measurements}

At 45 min after slaughter, $\mathrm{pH}$ was measured using a portable $\mathrm{pH}$ meter, and meat color was estimated by a colorimeter; Warner-Bratzler shear force was measured using a C-LM3 Digital Display tenderness instrument equipped with a shearing device (XIELI Sci. Co., Ltd.; Harbin, China) (Qin et al., 2014). After the carcass was aged for $24 \mathrm{~h}$, the longissimus lumborum muscles were isolated to evaluate drip loss using the method described by Honikel (1998) with modifications: muscle samples standardized for surface area $\left(5 \times 3 \times 2.5 \mathrm{~cm}^{3}\right)$ were suspended in an inflated plastic bag for $24 \mathrm{~h}$ at $4^{\circ} \mathrm{C}$.

\section{Determination of muscle fiber diameter and type}

The composition of muscle fiber type was determined by qRT-PCR. RNA was extracted from the longissimus dorsi muscle with TRIzol reagent (TaKaRa, China) using standard techniques. Total RNA $(1 \mu \mathrm{g})$ was reverse transcribed to synthesize cDNA using the Prime Script RT-Reagent Kit for RT-PCR. Real-time PCR amplifications were carried out on a Bio-Rad iQ5 by SYBR Premix Ex Taq ${ }^{\mathrm{TM}}$ II (TaKaRa) chemistry detection system under amplification conditions. mRNA data were quantified using the comparative threshold cycle (40 CT) method with slight modifications. The relative efficiency of each primer was included in the calculations. The specificity of the PCR amplification was verified by melting curve analysis. Details of the gene primers are presented in Table S1.

Muscle fiber diameter was determined by hematoxylin-eosin staining (Kim et al., 2013). Images were visualized and captured using a Nikon TE 2000 microscope (Nikon; Tokyo, Japan), and approximately 600 fibers per sample were counted.

\section{IMF content and fatty acid composition}

Muscle samples were obtained from the fourth-to-fifth intercostal space. IMF content was determined using the Weibull-Stoldt method (AOAC, 1997). Fatty acids from the longissimus lumborum muscle were detected based on their methyl ester content according to the method described by Park and Goins (1994). Separation of fatty acid methyl esters was performed by gas chromatography using a Tracegc Ultra system (Thermo Scientific; Waltham, MA, USA), and fatty acid composition was calculated using response factors derived from chromatographic standards (GLC-91, NU-CHEK; Elysian, MN, USA) of known composition. The results are reported as a percentage of the total fatty acid content.

\section{Free amino acid analysis}

The composition of free amino acids was detected by spectrophotometric analysis with ninhydrin reagent. Each amino acid sample was subjected to an automatic amino acid analyzer (model L-8900; Hitachi, Tokyo, Japan) for cation-exchange chromatography separation. Accuracy and repeatability of this analysis was ensured by the inclusion of a control sample of known amino acid composition with the samples prior to hydrolysis.

\section{Statistical analyses}

Statistical analyses were performed using SAS version 8.0 (SAS Inst. Inc.; Cary, NC, USA). Differences were considered significant when $\mathrm{P}<0.05$. 


\section{RESULTS AND DISCUSSION}

\section{Meat quality traits}

IMF significantly increased with increasing carcass weight $(\mathrm{P}<0.05)$, from 2.2 to $4.14 \%$ (Table 1). The overall $\mathrm{pH}$ was not significantly different among the three groups, and all values were within the normal range. The meat color value did not differ significantly among the three groups $(\mathrm{P}<0.05)$ (Table 1), which was inconsistent with the results of previous studies (Correa et al., 2006; Galián et al., 2009). Bamei pig is a plateau species, and its meat contains more redness, so the color value was almost the same in the three groups. The muscle fiber diameters in the three groups were 40.83, 48.96, and $58.33 \mu \mathrm{m}$, respectively (Figure 1). Group A contained the highest levels of MyHC I, IIA, and MyHC IIX mRNA among the three groups. Group $\mathrm{C}$ contained more oxidized muscle fibers than the other two groups, and showed the highest level of MyHC IIB mRNA expression (Figure 1). Ryu and Kim (2005) reported that fiber number and area percentage were not affected by carcass weight and loineye area. Other studies have showed that pigs with greater weights have the highest proportion of type IIB fibers, and thus, the proportion of type I and IIA fibers decreased (Bee, 2004). Our results are consistent with the observation that lower carcass weights are associated with higher percentages of oxidative muscle fiber.

Table 1. Meat quality traits of Bamei pigs.

\begin{tabular}{l|c|c|c}
\hline Item & $\mathrm{A}(60-69 \mathrm{~kg})$ & $\mathrm{B}(70-79 \mathrm{~kg})$ & $\mathrm{C}(80-90 \mathrm{~kg})$ \\
\hline Carcass weight $(\mathrm{kg})$ & $63.50 \pm 1.45^{\mathrm{a}}$ & $75.50 \pm 1.88^{\mathrm{b}}$ & $89.00 \pm 1.18^{\mathrm{c}}$ \\
\hline Ultimate pH & $5.55 \pm 0.21^{\mathrm{a}}$ & $5.72 \pm 0.19^{\mathrm{ab}}$ & $6.01 \pm 0.08^{\mathrm{b}}$ \\
\hline$L^{*}$ Value & $51.84 \pm 0.31^{\mathrm{a}}$ & $51.03 \pm 0.51^{\mathrm{b}}$ & $49.82 \pm 0.08^{\mathrm{a}}$ \\
\hline$A^{*}$ Value & $19.22 \pm 0.44^{\mathrm{a}}$ & $18.52 \pm 0.72^{\mathrm{b}}$ & $20.13 \pm 0.26^{\mathrm{c}}$ \\
\hline$B^{*}$ Value & $7.80 \pm 0.87^{\mathrm{a}}$ & $8.39 \pm 0.23^{\mathrm{b}}$ & $4.19 \pm 0.28^{\mathrm{a}}$ \\
\hline IMF content (\%) & $2.20 \pm 0.81^{\mathrm{a}}$ & $3.91 \pm 1.77^{\mathrm{b}}$ & $43.64 \pm 5.77^{\mathrm{c}}$ \\
\hline WBSF (N) & $61.16 \pm 3.48^{\mathrm{a}}$ & $51.63 \pm 7.10^{\mathrm{b}}$ & $90.56 \pm 3.41$ \\
\hline WHC (\%) & $92.24 \pm 1.61$ & $89.97 \pm 3.92$ & $3.76 \pm 0.32^{\mathrm{a}}$ \\
\hline Drip loss (\%) & $3.85 \pm 0.71^{\mathrm{a}}$ & $6.83 \pm 0.57^{\mathrm{b}}$ & $67.29 \pm 1.84$ \\
\hline Cooking percentage (\%) & $66.28 \pm 3.19$ & $65.26 \pm 2.11$ & \\
\hline
\end{tabular}

a,b,c Means within the same row with different superscript letters are significantly different $(\mathrm{P}<0.05)$. WBSF: Warner-Bratzler shear force; WHC: water holding capacity.
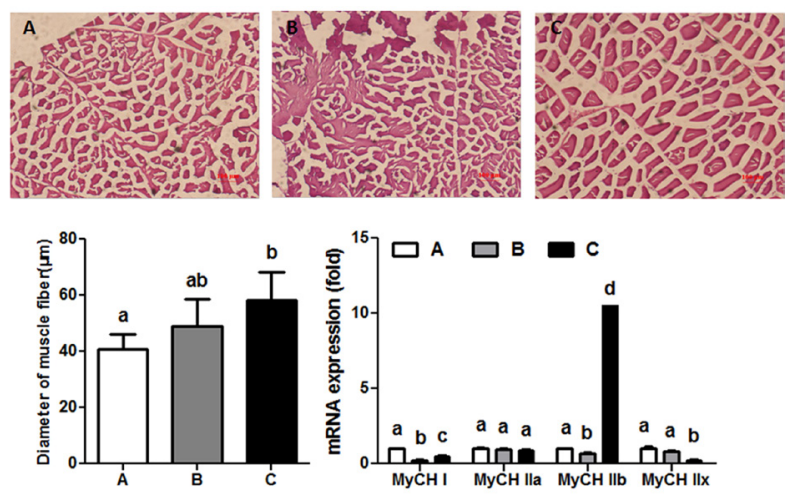

Figure 1. Determination of the diameter and percentage of muscle fiber in three groups of pigs. A. H\&E staining of muscle; B. diameter of muscle fiber; $\mathbf{C}$. quantification of muscle fiber types. Data are reported as means \pm standard error of the mean; different letters $(\mathrm{a}-\mathrm{e})$ indicate significantly different results $(\mathrm{P}<0.05)$.

Genetics and Molecular Research 15 (3): gmr.15037493 


\section{Fatty acid composition of IMF in the longissimus lumborum muscle}

A summary of the fatty acid profile and selected ratios are shown in Table 2 . The fatty acid composition of the longissimus lumborum muscle showed that the level of saturated fatty acids (SFA) in group B (37.24\%) was significantly lower than that in the other two groups, while the percentage of monounsaturated fatty acids was the highest $(54.12 \%)$, and mainly included oleic acid. Group B showed the highest polyunsaturated fatty acid/SFA (P:S) ratio $(\mathrm{P}<0.05)$. The content of the two major monounsaturated fatty acids (oleic and palmitoleic acids) in both group B and C was higher than in group A. Kouba et al. (2003) and Furman et al. (2010) found that the $\mathrm{C} 16: 1 \mathrm{n}-7$ and $\mathrm{C} 18: 1 \mathrm{n}-9$ in the longissimus muscle were higher according to increasing age and fattiness of pigs. Our results are not consistent with those previously reported, which may be due to the different range of body weights.

Table 2. Fatty acid content of the longissimus lumborum muscle from different pig carcasses.

\begin{tabular}{l|c|c|c}
\hline Item & $\mathrm{A}(60-69 \mathrm{~kg})$ & $\mathrm{B}(70-79 \mathrm{~kg})$ & $\mathrm{C}(80-90 \mathrm{~kg})$ \\
\hline SFA (\%) & $41.70 \pm 0.74^{\mathrm{a}}$ & $37.24 \pm 3.21^{\mathrm{b}}$ & $42.96 \pm 0.39^{\mathrm{a}}$ \\
\hline C14:0 (myristic acid) & $1.50 \pm 0.16^{\mathrm{a}}$ & $1.26 \pm 0.12^{\mathrm{b}}$ & $1.41 \pm 0.01^{\mathrm{ab}}$ \\
\hline C16:0 (palmitic acid) & $27.34 \pm 0.30$ & $24.68 \pm 1.47$ & $26.84 \pm 0.53$ \\
\hline C18:0 (stearic acid) & $14.12 \pm 0.08^{\mathrm{a}}$ & $11.30 \pm 1.63^{\mathrm{b}}$ & $13.45 \pm 1.27^{\mathrm{a}}$ \\
\hline MUFA (\%) & $50.76 \pm 1.14^{\mathrm{a}}$ & $54.12 \pm 3.31^{\mathrm{b}}$ & $48.75 \pm 1.89^{\mathrm{a}}$ \\
\hline C16:1n-7 (palmitoleic acid) & $3.29 \pm 0.33$ & $3.51 \pm 0.11$ & $3.32 \pm 0.54$ \\
\hline C18:1n-9 (oleic acid) & $45.46 \pm 1.56^{\mathrm{a}}$ & $50.61 \pm 3.20^{\mathrm{b}}$ & $47.44 \pm 0.60^{\mathrm{ab}}$ \\
\hline PUFA (\%) & $8.29 \pm 0.85^{\mathrm{a}}$ & $8.64 \pm 0.54^{\mathrm{a}}$ & $7.54 \pm 0.40^{\mathrm{b}}$ \\
\hline C18:2n-6 (linoleic acid) & $8.29 \pm 0.85^{\mathrm{a}}$ & $8.64 \pm 0.54^{\mathrm{a}}$ & $7.54 \pm 0.40^{\mathrm{b}}$ \\
\hline PUFA/SFA (P:S) ratio & $0.19 \pm 0.07^{\mathrm{a}}$ & $0.23 \pm 0.05^{\mathrm{b}}$ & $0.18 \pm 0.03^{\mathrm{a}}$ \\
\hline
\end{tabular}

${ }^{a, b}$ Means within the same line with different superscript letters are significantly different $(\mathrm{P}<0.05)$. SFA: saturated fatty acids; MUFA: monounsaturated fatty acids; PUFA: polyunsaturated fatty acids.

The fatty acid composition of food stuffs is of great importance to healthy human nutrition (Parunović et al., 2012). The P:S ratio is more beneficial to human health (Mapiye et al., 2011) than SFA and trans fatty acids, which are associated with an increased risk of cardiovascular disease and some cancers (Burlingame et al., 2009; Brouwer et al., 2010; USDA and HHS, 2010; Mapiye et al., 2011). While all the P:S ratios were acceptable $(\geq 0.4)$ (WHO, 2003), a higher P:S ratio was observed with lower IMF content in commercial pigs. Enser et al. (1996) showed that the pork with the highest proportion of C18:2n-6 (14.2\% of the total fatty acids) also had the highest $\mathrm{P}$ : $\mathrm{S}$ ratio (0.58), which is consistent with our results A comparison of the P:S ratio for the three groups, suggested that group B had the best proportions of fatty acids.

\section{Free amino acids composition}

The profile of free amino acids contributes to the taste of meat (Nishimura, 2009), and is known to be related to the development of particular tastes, flavors, or aromas, including saltiness, acid taste, and bitter taste (Guàrdia et al., 2008). Free amino acids can be classified into four categories: saccharinity (threonine, serine, glycine, and alanine), amino acids with sulfide (methionine and cysteine), fragrant amino acids (phenylalanine and tyrosine), and essential amino acids (threonine, valine, methionine, isoleucine, leucine, phenylalanine, histidine, lysine, and arginine) (Bailey and Ayling, 2007). The levels of all amino acid decreased as the pig weight increased; EAA, NEAA, DAA, AAA, BCAA followed the same trend. TAA, EAA, 
NEAA, and AAA were significantly higher in groups A and B than in group C, but there were no significant differences between groups A and B. Group A contained the highest level of aspartic and glutamic acids, which are known for the umami taste of loin. Arginine is known for its bitter taste and showed a small increasing trend, but no significant difference was found between the three groups (Table 3).

Table 3. Free Amino acid content in Bamei pigs muscle.

\begin{tabular}{|c|c|c|c|}
\hline Item & A (60-69 kg) & $\mathrm{B}(70-79 \mathrm{~kg})$ & $\mathrm{C}(80-90 \mathrm{~kg})$ \\
\hline Threonine $(\mathrm{Thr})^{\Delta}$ & $0.78 \pm 0.02$ & $0.76 \pm 0.05$ & $0.72 \pm 0.02$ \\
\hline Valine $(\mathrm{Val})^{\Delta \dagger}$ & $0.85 \pm 0.02$ & $0.84 \pm 0.05$ & $0.80 \pm 0.01$ \\
\hline Methionine $(\text { Met })^{\Delta}$ & $0.50 \pm 0.02$ & $0.44 \pm 0.05$ & $0.45 \pm 0.01$ \\
\hline Isoleucine (Ile) $)^{\Delta^{\dagger}}$ & $0.75 \pm 0.01$ & $0.73 \pm 0.05$ & $0.69 \pm 0.02$ \\
\hline Leucine (Leu) ${ }^{\dagger \Delta}$ & $1.34 \pm 0.03$ & $1.33 \pm 0.08$ & $1.24 \pm 0.03$ \\
\hline Phenylalanine $(\mathrm{Phe})^{\Delta *}$ & $0.82 \pm 0.02$ & $0.82 \pm 0.07$ & $0.75 \pm 0.02$ \\
\hline Lysine (Lys) ${ }^{\Delta}$ & $1.53 \pm 0.05$ & $1.48 \pm 0.10$ & $1.39 \pm 0.04$ \\
\hline Aspartic Acid (Asp) ${ }^{\ddagger \S}$ & $1.60 \pm 0.05$ & $1.56 \pm 0.09$ & $1.49 \pm 0.03$ \\
\hline Glutamic acid $(\mathrm{Glu})^{* \S}$ & $2.83 \pm 0.01^{\mathrm{a}}$ & $2.53 \pm 0.18^{b}$ & $2.71 \pm 0.08^{\mathrm{a}}$ \\
\hline Glycine (Gly) & $0.72 \pm 0.05$ & $0.75 \pm 0.04^{\mathrm{a}}$ & $0.67 \pm 0.01$ \\
\hline Alanine (Ala) $)^{\ddagger \S}$ & $0.94 \pm 0.03$ & $0.93 \pm 0.05$ & $0.87 \pm 0.01$ \\
\hline Arginine (Arg) $)^{\ddagger}$ & $1.08 \pm 0.04$ & $1.06 \pm 0.07$ & $0.98 \pm 0.03$ \\
\hline Serine $($ Ser) & $0.67 \pm 0.02$ & $0.65 \pm 0.04$ & $0.62 \pm 0.01$ \\
\hline Proline (Pro) ${ }^{\ddagger}$ & $1.19 \pm 0.07$ & $1.24 \pm 0.05$ & $1.17 \pm 0.01$ \\
\hline Cystine $(\mathrm{Cys})^{\ddagger}$ & $0.18 \pm 0.02$ & $0.20 \pm 0.01$ & $0.20 \pm 0.01$ \\
\hline Tyrosine $($ Tyr) & $0.57 \pm 0.01$ & $0.56 \pm 0.03$ & $0.53 \pm 0.02$ \\
\hline Histidine (His) ${ }^{\ddagger}$ & $0.67 \pm 0.02$ & $0.64 \pm 0.10$ & $0.56 \pm 0.01$ \\
\hline TAA & $16.92 \pm 0.49^{\mathrm{a}}$ & $16.62 \pm 1.11^{\mathrm{a}}$ & $15.58 \pm 0.37^{\mathrm{b}}$ \\
\hline EAA & $6.57 \pm 0.17^{\mathrm{a}}$ & $6.40 \pm 0.45^{\mathrm{a}}$ & $6.04 \pm 0.15^{\mathrm{b}}$ \\
\hline NEAA & $10.35 \pm 0.32^{\mathrm{a}}$ & $10.22 \pm 0.66^{\mathrm{a}}$ & $9.54 \pm 0.22^{b}$ \\
\hline DAA & $6.09 \pm 0.14$ & $5.77 \pm 0.36$ & $5.74 \pm 0.13$ \\
\hline AAA & $1.39 \pm 0.03^{\mathrm{a}}$ & $1.38 \pm 0.10^{\mathrm{a}}$ & $1.28 \pm 0.04^{\mathrm{b}}$ \\
\hline BCAA & $2.94 \pm 0.06$ & $2.90 \pm 0.18$ & $2.73 \pm 0.06$ \\
\hline DAA/TAA (\%) & $35.99 \pm 0.48^{\mathrm{c}}$ & $34.72 \pm 0.27^{\mathrm{a}}$ & $36.84 \pm 0.34^{\mathrm{b}}$ \\
\hline EAA/TAA (\%) & $38.83 \pm 0.45$ & $38.51 \pm 0.73$ & $38.77 \pm 0.20$ \\
\hline
\end{tabular}

${ }^{a, b, c}$ Means within the same row with different superscript letters are significantly different $(\mathrm{P}<0.05)$. TAA: total amino acids; ${ }^{\triangle}$ EAA: essential amino acids; ${ }^{2}$ NEAA: nonessential amino acids; §DAA: delicious amino acids; $\dagger$ BCAA: branched chain amino acids; *AAA: aromatic amino acids.

In conclusion, the carcass weight of Bamei pigs is related to muscle fiber characteristics, and has an influence on meat quality. In Bamei pigs, the longissimus lumborum in animals with a heavier carcass weight showed bigger muscle fiber diameters and lower levels of oxidized muscle fibers. The IMF also increased with increasing carcass weight, and group B contained the highest proportion of fatty acids. Total amino acid content decreased according to the increase or decrease of carcass weight. In conclusion, a suitable carcass weight was found to be important for meat quality. A comprehensive consideration of meat quality and economic benefits found the suitable slaughter weight of Bamei pigs to be $70-79 \mathrm{~kg}$.

\section{Conflicts of interest}

The authors declare no conflict of interest.

\section{ACKNOWLEDGMENTS}

Research supported by the "135" High-level Talents Training Project of Qinghai

Genetics and Molecular Research 15 (3): gmr.15037493 
Province, the National Natural Science Foundation of Qinghai Province (\#2015-ZJ-920Q), and the Agricultural Scientific and Technological Achievements Transformation and Demonstration Plan of Qinghai Province (\#2015-NK-512).

\section{REFERENCES}

AOAC (1997). Official method 991.36. Fat (crude) in meat and meat product. V: Official methods of analysis of AOAC International (Cunnif $\mathrm{P}$, ed.). 16th edn. AOAC International, Washington.

Bailey SW and Ayling JE (2007). Food and vitamin preparations containing the natural isomer of reduced folates. US 7172778 B2.

Bee G (2004). Effect of early gestation feeding, birth weight, and gender of progeny on muscle fiber characteristics of pigs at slaughter. J. Anim. Sci. 82: 826-836.

Brouwer IA, Wanders AJ and Katan MB (2010). Effect of animal and industrial trans fatty acids on HDL and LDL cholesterol levels in humans - a quantitative review. PLoS One 5: e9434. http://dx.doi.org/10.1371/journal. pone. 0009434

Burlingame B, Nishida C, Uauy R and Weisell R (2009). Fats and fatty acids in human nutrition: introduction. Ann. Nutr. Metab. 55: 5-7. http://dx.doi.org/10.1159/000228993

Correa JA, Faucitano L, Laforest JP, Rivest J, et al. (2006). Effects of slaughter weight on carcass composition and meat quality in pigs of two different growth rates. Meat Sci. 72: 91-99. http://dx.doi.org/10.1016/j.meatsci.2005.06.006

Enser M, Hallett K, Hewitt B, Fursey GA, et al. (1996). Fatty acid content and composition of english beef, lamb and pork at retail. Meat Sci. 42: 443-456. http://dx.doi.org/10.1016/0309-1740(95)00037-2

Furman M, Malovrh Š, Levart A and Kovač M (2010). Fatty acid composition of meat and adipose tissue from Krškopolje pigs and commercial fatteners in Slovenia. Arch. Tierzucht 53: 73-84.

Galián M, Poto A and Peinado B (2009). Carcass and meat quality traits of the Chato Murciano pig slaughtered at different weights. Livest. Sci. 124: 314-320. http://dx.doi.org/10.1016/j.livsci.2009.02.012

Guàrdia MD, Guerrero L, Gelabert J, Gou P, et al. (2008). Sensory characterisation and consumer acceptability of small calibre fermented sausages with $50 \%$ substitution of $\mathrm{NaCl}$ by mixtures of $\mathrm{KCl}$ and potassium lactate. Meat Sci. 80: 1225-1230. http://dx.doi.org/10.1016/j.meatsci.2008.05.031

Guo YY, Hou SZ, Yang BC, et al. (2012). Effect of three Pig breeds as male parent on the reproductive performances of Qinghai Huzhu Bamei Pig. J. Anhui Agric. Sci. 40: 11697-11698.

Honikel KO (1998). Reference methods for the assessment of physical characteristics of meat. Meat Sci. 49: 447-457. http://dx.doi.org/10.1016/S0309-1740(98)00034-5

Jin YC (2006). The protection and utilization of Qinghai Bamei Pig. Swine Ind. Sci. 23: 70-74.

Kim GD, Kim BW, Jeong JU, Hur SJ, et al. (2013). Relationship of carcass weight to muscle fiber characteristics and pork quality of crossbred (Korean native black pig x Landrace) F2 pigs. Food Bioproc. Techol. 6: 522-529. http://dx.doi. org/10.1007/s11947-011-0724-2

Kouba M, Enser M, Whittington FM, Nute GR, et al. (2003). Effect of a high-linolenic acid diet on lipogenic enzyme activities, fatty acid composition, and meat quality in the growing pig. J. Anim. Sci. 81: 1967-1979.

Mapiye C, Chimonyo M, Dzama K, Hugo A, et al. (2011). Fatty acid composition of beef from Nguni steers supplemented with Acacia karroo leaf-meal. J. Food Compos. Anal. 24: 523-528. http://dx.doi.org/10.1016/j.jfca.2011.01.018

Nishimura T (2009). Influence of Endopeptidases and Aminopeptidases on the Production of Taste Peptides and Free Amino Acids in Muscle Foods. ACS Symposium Series 37: 419-430.

Park PW and Goins RE (1994). In situ preparation of fatty acid methyl esters for analysis of fatty acid composition in foods. J. Food Sci. 59: 1262-1266. http://dx.doi.org/10.1111/j.1365-2621.1994.tb14691.x

Parunović N, Petrović M, Matekalo-Sverak V, Mijatović M, et al. (2012). Fatty acid profile and cholesterol content of m: longissimus of free-range and conventionally reared Mangalitsa pigs. S. Afr. J. Anim. Sci. 42: 101-113.

Pfeuffer M (2001). Physiologie effects of individual fatty acids in animal and human body, with particular attention to coronary heart disease risk modulation. Arch. Tierzucht 44: 89-98.

Qin J, Yang DS, Zhang XH, Wang JQ, et al. (2014). Measurement and Analysis of Horse Meat Tenderness in Yill Area 51: $577-582$

Raes K, De Smet S and Demeyer D (2004). Effect of dietary fatty acid on incorporation of long chain polyunsaturated fatty acids and conjugated linoleic acid in lamb, beef and pork meat: a review. Anim. Feed Sci. Technol. 113: 199-221. $\underline{\text { http://dx.doi.org/10.1016/j.anifeedsci.2003.09.001 }}$

Rehfeldt C, Fiedler I, Dietl G and Ender K (2000). Myogenesis and postnatal skeletal muscle cell growth as influenced by

Genetics and Molecular Research 15 (3): gmr.15037493 
selection. Livest. Prod. Sci. 66: 177-188. http://dx.doi.org/10.1016/S0301-6226(00)00225-6

Ryu YC and Kim BC (2005). The relationship between muscle fiber characteristics, postmortem metabolic rate, and meat quality of pig longissimus dorsi muscle. Meat Sci. 71: 351-357. http://dx.doi.org/10.1016/j.meatsci.2005.04.015

Ryu YC and Kim BC (2006). Comparison of histochemical characteristics in various pork groups categorized by postmortem metabolic rate and pork quality. J. Anim. Sci. 84: 894-901.

USDA and HHS (2010). Dietary Guidelines for Americans 2010. Department of Health and Human Services (HHS)/ Department of Agriculture (USDA) Available at [http://www.cnpp.usda.gov/DGAs2010-DGAC Report.htm].

WHO (2003). Diet, nutrition and the prevention of chronic diseases. Report of a joint WHO/FAO expert consultation. WHO Technical Report Series, Geneva.

Yang BC and Gun SB (2007). Current situation and in vivo protection method of Qinghai Bamei Pig. Chin. Qighai J. Anim. Vet. Sci. 37: 31-32.

Yang BC, Zhou JP, Wu KX, Liu YF (2010). Determination of fattening and carcass traits in Different Crossbred swine. Heilongjiang Anim. Sci. Vet. Med. 2: 52-53.

Yang BC, Liu YF and Lei Y (2011). Production performance measurement of Qinghai Bamei Pig Crossbreeding. Anim. Husbandry Vet. Med. 43: 35-37.

Yang GS and Song Y (1991). Study on the chemical composition of the meat of Bamei pig meat. J. Northwest Univ. 4: $38-42$.

\section{Supplementary material}

Table S1. Primers used for real-time PCR analysis. 